\title{
Improved support vector machine algorithm based on the influence of Gestational Diabetes Mellitus on the outcome of perinatal outcome by ultrasound imaging
}

\author{
Hehua Liu', Jie Liu
}

\begin{abstract}
Objectives: In order to understand the incidence and epidemiological characteristics of gestational diabetes mellitus, the ultrasound imaging of support vector machine processing algorithm was used to clarify the outcome of maternal and neonatal gestational diabetes mellitus.

Methods: This study selected clinical data of 12,190 pregnant women who were hospitalized for delivery, and were divided into diabetic group (1268 cases) and control group (10922 cases) according to the diagnosis of gestational diabetes. The study was conducted from January 1, 2012 to December 31, 2019. Colour Doppler ultrasound was performed to record fatal umbilical artery and brain the middle arteries and uterine arteries which are effective indicators of measuring fatal intrauterine conditions. Chi-square test was used to compare the rates between groups, and multivariate logistic regression was used for labour outcomes.

Results: The incidence of diabetes during pregnancy is about $10.4 \%(1268 / 12190)$. Senior citizens and women suffering from obesity increase the risk of gestational diabetes, maternal hypertension disorders in pregnancy, premature rupture of membranes, oligohydramnios, fatal distress, multiple births, malpresentation risk increased significantly $(P<0.05)$ than the control group. In gestational diabetes caesarean section rate was significantly higher (61.0\% vs46.4\%). Caesarean new born 5 -minute Apgar score was significantly lower than the control group $(P<0.05)$.

Conclusion: In maternal gestational diabetes in high risk pregnancies, complications of pregnancy significantly increase the importance of enhancing weight management and blood glucose monitoring to reduce complications.
\end{abstract}

KEYWORDS: Gestational diabetes; Pregnancy complications; Umbilical artery; Middle cerebral artery; Uterine artery; Ultrasound examination.

doi: https://doi.org/10.12669/pjms.37.6-WIT.4855

How to cite this:

Liu H, Liu J. Improved support vector machine algorithm based on the influence of Gestational Diabetes Mellitus on the outcome of perinatal outcome by ultrasound imaging. Pak J Med Sci. 2021;37(6):1625-1629. doi: https://doi.org/10.12669/pjms.37.6-WIT.4855

This is an Open Access article distributed under the terms of the Creative Commons Attribution License (http://creativecommons.org/licenses/by/3.0), which permits unrestricted use, distribution, and reproduction in any medium, provided the original work is properly cited.

1. Hehua Liu, Attending Physician.

Department of Obstetrics,

2. Jie Liu, Attending Physician. Department of Emergency Medicine,

1,2: East Hospital of The Fourth Hospital, Shijiazhuang City, 050011, China.

Correspondence:

Jie Liu,

Department of Emergency Medicine,

East Hospital of the Fourth Hospital, Shijiazhuang City, 050011, China.

E-mail: liujiedemo@126.com

* Received for Publication:

* Revision Received:

* Second Revision Received:

* Final Revision Accepted:
April 2, 2021

June 9, 2021

June 15, 2021

July 7, 2021

\section{INTRODUCTION}

Previous studies have shown that the risk of pregnancy complications of GDM pregnant women, such as premature birth, giant infants, and hypertension during pregnancy, is significantly increased..$^{1-3}$ The increase in the incidence of large size infants also increases the rate of caesarean section. Complications also increased significantly, manifested as hypoglycaemia, respiratory distress syndrome, jaundice, fatal growth restriction, and increased morbidity of children less than gestational age, which resulted in a significant increase in the 
rate of neonatal conversion to ICU. ${ }^{4-7}$ Therefore, the diagnosis of GDM and the monitoring and management of blood glucose have a great impact on pregnancy outcomes. ${ }^{8,9}$ At present, there are not many cross-sectional studies on the perinatal outcome of GDM in China. ${ }^{10,11}$ This study collected the data of hospitalized women who delivered in the hospital, and analyzed the data to understand the incidence of GDM in the hospital under the new GDM diagnostic standard. We also studied the related maternal complications, maternal and neonatal perinatal outcomes.

\section{METHODS}

We collected clinical data of all hospitalized deliveries from January 1, 2012 to December 31, 2019 patients and puerperal $\geq 24$ weeks of gestation, including general conditions such as age, education level, and pregnancy times, delivery methods and complications and the condition of the new born. All the clinical data were collected from medical records and the study was approved by the hospital ethics committee.

A total of 12,190 patients clinical data were collected and divided into a GDM group (1268 cases) and a control group (10922 cases) according to whether GDM was diagnosed. GDM diagnosis was based on the 2010 IADPSG to develop new diagnostic criteria: all non-diabetic pregnant women routinely undergo $75 \mathrm{~g}$ oral glucose tolerance test (OGTT) at 24 to 28 weeks of gestation, meeting or exceeding at least one of the following indicators: fasting blood glucose, after taking sugar 1 The 2-hour blood glucose was $5.1 \mathrm{mmol} / \mathrm{L}$, $10.0 \mathrm{mmol} / \mathrm{L}$ and $8.5 \mathrm{mmol} / \mathrm{L}$, respectively, which was the diagnosis of GDM. Prenatal haemorrhage includes placenta previa, placental abruption, and rupture of blood sinus at the edge of placenta. Pre-exposed abnormality refers to pre-exposed pre-existing abnormalities including breech and lateral position, excluding occipital abnormalities at birth, such as persistent lateral and posterior occipital positions. ${ }^{12,13}$

Ultrasound examination. Using E8 color ultrasound Doppler ultrasound diagnostic equipment from the US company GE, the probe frequency is 2.5 to $3.5 \mathrm{MHz}$ Obstetrical conditions were adopted. UMA, MCA and UTA were tested after routine obstetrical examination. The sound beam was parallel to the direction of blood flow as far as possible. The correction angle was less than $20^{\circ}$. The pulse Doppler sampling volume was selected according to the thickness of the vessel diameter. The $3 \mathrm{~mm}$ measurement was selected for the MCA measurement. When testing UMA, choose a sample within $5-\mathrm{cm}$ of the place where the placenta is inserted, adjust the position and angle of the probe so that the sound beam is parallel to the direction of blood flow. After obtaining a stable spectrum image, the blood flow parameters are measured by stopping the frame. Of the foetus through the UTA and UMA, MCA flow spectrum is measured separately collecting the blood vessel and the following recording parameters: Pulsatilityindex (PI), Resistance in- deck (RI), systolic flow / diastolic flow (S / D). The perinatal follow-up content includes the birth method, the fatal perinatal outcome of the new born 1minAgar score, birth weight, neonatal admission to the NICU ward and mortality rate, all data were tabulated and statistically analyzed.

Statistical Analysis: After all the data are entered into the computer to establish a database for statistical analysis was done using SPSS18.0. Normally distributed data were expressed as mean \pm standard deviation, skewness distribution data were median and interquartile. Continuous variables were skewed using Mann-Whitney U analysis, $\chi 2$ test was used to compare the frequency. SVM is the optimal classification surface in linear separable situation evolved. The classification line equation is, and we can normalize it to make the linearly separable sample set $B$.

$$
\begin{gathered}
\left(\boldsymbol{x}_{i}, y_{i}\right), i=1, \ldots, n \quad \boldsymbol{x} \in R^{d}, y \in\{+1,-1\}, \text { satisfy } \\
\left.y_{i}\left[\boldsymbol{w} \cdot \boldsymbol{x}_{i}\right)+b\right]-1 \geq 0, \quad i=1, \cdots, n \text { (1) } \\
Q(\alpha)=\sum_{i=1}^{n} \alpha_{i}-\frac{1}{2} \sum_{i, j=1}^{n} \alpha_{i} \alpha_{j} y_{i} y_{j}\left(\boldsymbol{x}_{i} \cdot \boldsymbol{x}_{j}\right) \\
f(\boldsymbol{x})=\operatorname{sgn}\{(\boldsymbol{w} \cdot \boldsymbol{x})+b\}=\operatorname{sgn}\left\{\sum_{i=1}^{n} \alpha_{i}^{*} y_{i}\left(\boldsymbol{x}_{i} \cdot \boldsymbol{x}\right)+b^{*}\right\}
\end{gathered}
$$

The summation in the formula is actually only performed on the support vector. $b{ }^{*}$ is the classification threshold, which can be obtained by any one of the support vectors (satisfying the equal sign in (1)), or by the median of any pair of support vectors in the two categories.

$$
Q(\alpha)=\sum_{i=1}^{n} \alpha_{i}-\frac{1}{2} \sum_{i, j=1}^{n} \alpha_{i} \alpha_{j} y_{i} y_{j} K\left(\boldsymbol{x}_{i}, \boldsymbol{x}_{j}\right)
$$

And the corresponding classification function also becomes

$$
f(\boldsymbol{x})=\operatorname{sgn}\left(\sum_{i=1}^{n} \alpha_{i}^{*} y_{i} K\left(\boldsymbol{x}_{i}, \boldsymbol{x}\right)+b^{*}\right)
$$

This is the support vector machine. If you want to find a certain balance between empirical risk 
Hehua Liu et al.

Table-I: Study population characteristics [n (\%)].

\begin{tabular}{lccc}
\hline Project & GDM group & Control group & $P$ \\
\hline History of poor pregnancy & $31(2.4)$ & $185(1.7)$ & $>0.05$ \\
Obesity & $366(31.0)$ & $1897(18.2)$ & $<0.01$ \\
Multiple births & $331(2.6)$ & $192(1.8)$ & $<0.05$ \\
Premature delivery & $92(7.3)$ & $702(6.4)$ & $>0.05$ \\
Premature rupture of membranes & $306(24.1)$ & $2929(26.8)$ & $<0.05$ \\
Hypertension during pregnancy & $126(9.9)$ & $590(5.4)$ & $<0.01$ \\
Fatal growth restriction & $29(2.3)$ & $307(2.8)$ & $>0.05$ \\
Prenatal bleeding & $33(2.6)$ & $232(2.1)$ & $>0.05$ \\
Abnormal & $89(7.0)$ & $606(5.5)$ & $<0.05$ \\
Too little amniotic fluid & $32(2.5)$ & $422(3.9)$ & $<0.05$ \\
Fatal distress & $202(15.9)$ & $2545(23.3)$ & $<0.01$ \\
\hline
\end{tabular}

Note: Missing data; 30 cases of adverse pregnancy history, 484 obese patients, and 90 cases of fatal growth restriction.

and generalization performance, you can allow the existence of misclassified samples by introducing a positive relaxation factor $\xi i$. At this time, the constraint (1) becomes

$$
\left.y_{i}\left[\boldsymbol{w} \cdot \boldsymbol{x}_{i}\right)+b\right]-1+\xi_{i} \geq 0, \quad i=1, \cdots, n \text { (6) }
$$

And the penalty term $C \sum_{i=1}^{n} \xi_{i}$ is added to the goalminimizing $\frac{1}{2}\|\boldsymbol{w}\|^{2}$ that the Wolf dual problem can be written as:

$$
Q(\alpha)=\sum_{i=1}^{n} \alpha_{i}-\frac{1}{2} \sum_{i, j=1}^{n} \alpha_{i} \alpha_{j} y_{i} y_{j} K\left(\boldsymbol{x}_{i}, \boldsymbol{x}_{j}\right)
$$

\section{RESULTS}

The study included 12,190 pregnant women, women with GDM 1268 cases, the incidence being $10.4 \%$. The average age of GDM women (31 years old) was significantly higher $(30,1)$ ( $\mathrm{P}<0.001)$; GDM group mean gestational age (38 years) was significantly less than the control group (39) (P $<0.001)$. GDM maternal obesity, pregnancy induced hypertension, premature rupture of membranes, oligohydramnios, fatal distress, oligohydramnios, multiple pregnancy, the risk malpresentation than the control group increased significantly $(\mathrm{P}$ $<0.05)$. GDM mother's adverse pregnancy history, premature birth, fetal growth restriction, prenatal risk of haemorrhage than the control group, the difference was not significant (Table-I).

As regards characteristics of GDM maternal pregnancy outcomes. GDM mothers' children weight was significantly higher $(\mathrm{P}<0.05)$. Comparison of neonatal sex postpartum haemorrhage and maternal morbidity two groups showed that the difference was not statistically significant. 1,269 cases of maternal GDM, caesarean delivery 773 cases $(61.0 \%)$, compared with the control group (46.4\%) was significantly higher; natural vaginal delivery 466 cases $(36.8 \%)$, vaginal delivery 29 cases $(2.3 \%)$, compared with the control group decreased significantly. Compared with the control group, the 1-minute Apgar score of GDM maternal neonates was less than $7(0.2 \%)$, and there was no significant difference, while 13 cases $(1.0 \%)$ of 5-minute Apgar score was less than 7 (Table-II).

Table-II: Comparison of the delivery outcomes of the two groups.

\begin{tabular}{lccc}
\hline Project & $\begin{array}{c}\text { GDM } \\
\text { group }\end{array}$ & $\begin{array}{c}\text { Control } \\
\text { group }\end{array}$ & $P$ \\
\hline Huge & $130(10.3)$ & $720(6.6)$ & $<0.01$ \\
Male tire & $692(54.6)$ & $5701(52.2)$ & $>0.05$ \\
Vaginal delivery & $466(36.8)$ & $5429(49.7)$ & $<0.01$ \\
Surgical delivery & $29(2.3)$ & $425(3.9)$ & $<0.01$ \\
Caesarean section & $773(61.0)$ & $5068(46.4)$ & $<0.01$ \\
$\begin{array}{l}\text { Apgar score }<7 \text { in } \\
\text { 1 minute }\end{array}$ & $3(0.2)$ & $23(0.2)$ & $>0.05$ \\
$\begin{array}{l}\text { Apgar score }<7 \text { in } \\
\text { 5 minutes }\end{array}$ & $13(1.0)$ & $1(0.0)$ & $<0.01$ \\
$\begin{array}{l}\text { Postpartum } \\
\text { haemorrhage }\end{array}$ & $116(9.1)$ & $929(8.5)$ & $>0.05$ \\
\hline
\end{tabular}

Note: Missing data: 71 cases of fatal weight, 68 cases of Apgar score in 1 minute, and 125 cases of Apgar score in 5 minutes. 
Table-III: Comparison of indications for caesarean section [n (\%).

\begin{tabular}{lccc}
\hline $\begin{array}{l}\text { Caesarean section } \\
\text { indications }\end{array}$ & $\begin{array}{c}\text { Control } \\
\text { group }\end{array}$ & $\begin{array}{c}\text { GDM } \\
\text { group }\end{array}$ & $P$ \\
\hline No indication & $994(9.1)$ & $161(12.7)$ & $<0.01$ \\
Fatal distress & $717(6.6)$ & $70(5.5)$ & $>0.05$ \\
Stagnation of labour & $593(5.4)$ & $75(5.9)$ & $>0.05$ \\
$\begin{array}{l}\text { Hip, horizontal } \\
\text { position }\end{array}$ & $540(4.9)$ & $78(6.2)$ & $>0.05$ \\
Scarred uterus & $404(3.7)$ & $67(5.3)$ & $<0.01$ \\
Elderly maternal & $399(3.7)$ & $114(9.0)$ & $<0.01$ \\
Huge & $359(3.3)$ & $65(5.1)$ & $<0.01$ \\
Preeclampsia & $232(2.1)$ & $49(3.9)$ & $<0.01$ \\
Multiple births & $157(1.4)$ & $30(2.4)$ & $<0.05$ \\
Prenatal bleeding & $143(1.3)$ & $18(1.4)$ & $>0.05$ \\
\hline
\end{tabular}

There are two sets of indications for caesarean section analysis. In order to clarify the reason for the significant increase in the cesarean section rate in the GDM group, the study further compared the two groups of cesarean section indications. The results showed that the rate of diabetic cesarean section without medical indications was significantly higher than that of the diabetic group without medical indications. Obese women who had a Caesarean section accounted for $37.1 \%$ (56/151), which was significantly higher $(21.4 \%$, 204/952). Secondly, the characteristics of diabetic uterine scars, elderly women, older children, preeclampsia, multiple pregnancy, cesarean section, etc. were also significantly increased $(\mathrm{P}<0.05)$ (Table-III).

Comparison of Doppler ultrasound results showed that the study group uterine artery PI, RI had no statistically significant difference compared with control group (P>0.05), Table IV-VI.

Various pregnancy comorbidities can cause spasm of uterine myometrium and decidual layer

Table-IV: PI, RI, S/D comparison of fatal umbilical artery.

\begin{tabular}{lccc}
\hline & $P I$ & $R I$ & $S / D$ \\
\hline Research group & $1.34 \pm 0.33$ & $0.68 \pm 0.05$ & $3.70 \pm 0.87$ \\
Control group & $0.76 \pm 0.13$ & $0.59 \pm 0.06$ & $2.45 \pm 0.42$ \\
$\mathrm{t}$ & 12.252 & 8.167 & 9.627 \\
$\mathrm{P}$ & $<0.05$ & $<0.05$ & $<0.05$ \\
\hline
\end{tabular}

Table-V: PI, RI, S / D comparison of fatal middle cerebral artery in two groups.

\begin{tabular}{lccc}
\hline & $P I$ & $R I$ & $S / D$ \\
\hline Research group & $1.09 \pm 0.36$ & $0.64 \pm 0.17$ & $3.22 \pm 1.03$ \\
Control group & $1.25 \pm 0.34$ & $0.76 \pm 0.29$ & $3.95 \pm 0.96$ \\
$\mathrm{t}$ & 2.322 & 2.49 & 3.729 \\
$\mathrm{P}$ & $<0.05$ & $<0.05$ & $<0.05$ \\
\hline
\end{tabular}

arteries, thickening of the tube wall, reduction of the inner diameter of the uterine cavity. Decreased blood flow is manifested by increased S/D of the umbilical artery. The increased resistance of the placental circulation directly affects the exchange of nutrients and oxygen between the fatal circulation and maternal blood, resulting in different degrees of intrauterine hypoxia in the foetus. The statistical significance $(\mathrm{P}<0.05)$ suggests that the combined application of umbilical artery blood flow parameters to predict fatal intrauterine status has a high clinical value.

\section{DISCUSSION}

In this study, the caesarean section rate of gestational diabetes was significantly higher, reaching $61 \%$. Obese elderly women have an increased risk of gestational diabetes, which may lead to maternal hypertension, premature rupture of membranes, oligohydramnios, and fatal distress. ${ }^{14-16}$

Obesity during pregnancy is a high risk factor for GDM. In this study, the perinatal outcome of GDM women was analyzed. ${ }^{17,18}$ Previous studies have shown that, age, high BMI, excessive weight during pregnancy, and high blood pressure are risk factors for GDM. Pinheiro ${ }^{19-20}$ have shown that, older woman (older than 35 years old) are more likely to be overweight and suffer from gestational diabetes and high blood pressure, and they prefer to have caesarean section, with poor perinatal period, which is consistent with the results of this study. The perinatal mortality rate

Table-VI: PI, RI, S / D comparison of two groups of uterine arteries.

\begin{tabular}{lccc}
\hline & $P I$ & $R I$ & $S / D$ \\
\hline Research group & $0.60 \pm 0.17$ & $0.43 \pm 0.09$ & $1.88 \pm 0.06$ \\
Control group & $0.55 \pm 0.13$ & $0.42 \pm 0.08$ & $1.71 \pm 0.22$ \\
$\mathrm{t}$ & 1.701 & 0.599 & 5.088 \\
$\mathrm{P}$ & $>0.05$ & $>0.05$ & $<0.05$ \\
\hline
\end{tabular}


of older women is higher. In the present study, the gestational week of GDM women was significantly lower than that of the control group. This may be why the guidelines recommend GDM women to induce labor at 40 weeks.

\section{CONCLUSIONS}

Studies have shown that there is a statistical difference between low birth weight infants and neonates in the control group and the low group study. There were neonatal deaths in the study Group-2 and no neonatal deaths in the control group. It also showed that the difference between the study group and the control group in perinatal adverse outcomes was statistically significant, and the abnormal Doppler spectrum is significantly correlated with the adverse perinatal outcomes. As such the three-vascular Doppler spectrum hemodynamic examination is closely related to predicting adverse perinatal outcomes and reducing pregnancy risks.

\section{REFERENCES}

1. Radzicka S, Pietryga M, Iciek R, Brązert J. The role of visfatin in pathogenesis of gestational diabetes (GDM). Ginekol Pol. 2018;89(9):518-521. doi: 10.5603/GP.a2018.0088

2. Ponzo V, Ferrocino I, Zarovska A, Amenta MB. The microbiota composition of the offspring of patients with gestational diabetes mellitus (GDM). PLoS One. 2019;14(12):e0226545. doi: 10.1371/journal.pone.0226545

3. Caissutti C, Berghella V, Scientific Evidence for Different Options for GDM Screening and Management: Controversies and Review of the Literature. Biomed Res Int. 2017:2746471 doi: 10.1155/2017/2746471

4. Muhwava LS, Murphy K, Zarowsky C, Levitt N. Experiences of lifestyle change among women with gestational diabetes mellitus (GDM): A behavioural diagnosis using the COM-B model in a low-income setting. PLoS One. 2019;14(11):e0225431. doi: 10.1371/journal. pone. 0225431

5. Trond HD, Ragnhild E. Long-term psychosocial consequences of surgical congenital malformations. Semin Pediatr Surg. 2017;26(5):286-294. doi: 10.1053/j. sempedsurg.2017.09.009

6. Natamba BK, Namara AA, Nyirenda MJ. Burden risk factors and maternal and offspring outcomes of gestational diabetes mellitus (GDM) in sub-Saharan Africa (SSA): A systematic review and meta-analysis. BMC Pregnancy Childbirth. 2019;19(1):450. doi: 10.1186/s12884-019-2593-Z

7. Lacroix M, Lizotte F, Hivert MF, Geraldes P, Perron P. Calcifediol Decreases Interleukin-6 Secretion by Cultured Human Trophoblasts From GDM Pregnancies. J Endocr Soc. 2019;3(11):2165-2178. doi: 10.1210/js.2019-00181

8. Filardi T, Catanzaro G, Mardente S, Zicari A. Non-Coding RNA: Role in Gestational Diabetes Pathophysiology and Complications. Int J Mol Sci. 2020;21(11):4020. doi: 10.3390/ ijms21114020
9. Guimaraes MF, Brandao AH, Rezende CA, Cabral AC, Brum AP, et al. Assessment of endothelial function in pregnant women with preeclampsia and gestational diabetes mellitus by flow-mediated dilation of brachial artery. Arch Gynecol Obstet. 2014;290(3):441-447. doi: 10.1007/s00404-014-3220-x

10. Schmidt WA. The ultrasound halo sign of temporal arteries: is it always giant cell arteritis? Rheumatology (Oxford). 2019;58(11):1898-1899. doi: 10.1093/rheumatology/kez355

11. Scarpetta SG. The first known fossil Uma: ecological evolution and the origins of North American fringe-toed lizards. BMC Evol Biol. 2019;19(1):178. doi: 10.1186/ s12862-019-1501-5

12. Van Himbeeck RAF, Huizinga W, Roessink I, Peeters ETHM. Behavioral patterns of two fiddler crab species Uca rapax and Uca tangeri in a seminatural mangrove system. Zoo Biol. 2019;38(4):343-354. doi: 10.1002/zoo.21488

13. Barbara L, Morton BB, Liu CL, Hafsatou D, Judy ES. Validation of Severe Maternal Morbidity on the US Certificate of Live Birth. Epidemiology. 2018;29(4):e31-e32. doi: 10.1097/EDE.0000000000000828

14. Douglas AS, Liu MF, Patrick SK. Portal Hypertension and Related Complications: Diagnosis and Management. Mayo Clin Proc. 2019;94(4):714-726. doi: 10.1016/j. mayocp.2018.12.020

15. Thuring A, Karin Kallen K, Jonas B, Jansson T, Karel M Doppler audio signal analysis as an additional tool in evaluation of umbilical artery circulation. Ultraschall Der Medizin. 2018;38(5):549-555. doi: 10.1055/s-0035-1553302

16. Simmons D. GDM and Nutrition-Answered and Unanswered Questions-There's More Work to Do! Nutrients. 2019;11(8):1940. doi: 10.3390/nu11081940

17. $\mathrm{Xu} \mathrm{T}, \mathrm{He} \mathrm{Y}$, Dainelli L. Healthcare intervention for the prevention and control of gestational diabetes mellitus in China: a scoping review. BMC Pregnancy Childbirth. 2017;17(1):171. doi: 10.1186/s12884-017-1353-1

18. Juan J, Yang H. Prevalence, Prevention, and Lifestyle Intervention of Gestational Diabetes Mellitus in China. Int J Environ Res Public Health. 2020;17(24):9517. doi: 10.3390/ ijerph17249517

19. Yang L, Jesse TY. Improved contrast for high frame rate imaging using coherent compounding combined with spatial matched filtering. Ultrasonics. 2017;78:152-161. doi: 10.1016/j.ultras.2017.03.015

20. Pinheiro RL, Areia AL, Mota Pinto A, Donato H. Advanced Maternal Age: Adverse Outcomes of Pregnancy, A MetaAnalysis. Acta Med Port. 2019;32(3):219-226. doi: 10.20344/ amp.11057

\section{Authors Contribution:}

HL: Conceived the study, literature review, drafting the manuscript, data analysis,

JL: Takes the responsibility and is accountable for all aspects of the work in ensuring that questions related to the accuracy or integrity of any part of the work are appropriately investigated and resolved. 